\title{
México ante el dilema del "tercer país seguro" en el contexto de los Protocolos de Protección a Migrantes (MPP)
}

\author{
Mexico faced with the dilemma of the "safe third \\ country" in the context of the Migrant Protection \\ Protocols (MPP)
}

\author{
Jorge Morales Cardiel y Chantal Lucero Vargas \\ Universidad Autónoma de Zacatecas, México e Instituto de Investigaciones Sociales \\ de la Universidad Autónoma de Baja California, México
}

\begin{abstract}
Resumen
La implementación de los Protocolos de Protección a Migrantes (MPP), conocido en México como el programa "Quédate en México", fue una acción del gobierno de Estados Unidos mediante la cual ciertas personas extranjeras que ingresaban o buscaban admisión a dicho país desde México, de forma iregular, podían ser devueltas a este país para esperar la resolución a su solicitud de admisión (asilo). El gobierno de México convino, por razones humanitarias, recibirlos y permitir una estadía en el país durante la vigencia del trámite migratorio legal. Esta situación de reasentamiento convirtió a México en un supuesto "tercer país seguro", un hecho que de entrada no considera el largo expediente de violaciones de derechos humanos hacia los migrantes en tránsito por territorio mexicano, por consecuencia el presente trabajo presenta una reconceptualización de la migración forzada a raíz de este tipo de acuerdos.
\end{abstract}

Palabras clave: Migración forzada, tercer país seguro, reasentamiento, derechos humanos, Asilo.

\begin{abstract}
The implementation of the Migrant Protection Protocols (MPP), known in Mexico as the "Stay in Mexico" program, was an action of the United States government through which certain foreigners who entered or sought admission to that country from Mexico, irregularly, could be returned to this country to await the resolution of their application for admission (asylum). The government of Mexico agreed, for humanitarian reasons, to receive them and allow them a stay in the country during the validity of the legal immigration process. This resettlement situation turned Mexico into a supposed "safe third country", a fact that does not initially consider the long record of human rights violations towards migrants in transit through mexican territory. Consequently, this paper presents a reconceptualization of the forced migration as a result of this type of agreement.
\end{abstract}

Key words: Forced migration, safe third country, resettlement, human rights, Asylum.

Artículo recibido el 20 de marzo de 2020 y aprobado el 19 de diciembre de 2020. 


\section{INTRODUCCIÓN}

$\mathrm{L}$ a implementación de los Protocolos de Protección al Migrante por parte del Gobierno de los Estados Unidos, representó una acción que convirtió a México en un tercer país seguro de facto, por no decir en el guardián incondicional de la frontera sur estadounidense, algo que no es completamente nuevo ya que simboliza un capítulo más una larga novela de subordinación mexicana en el tema migratorio hacia su par norteamericano. Sin mediar ningún acuerdo entre el gobierno estadounidense y mexicano y, al conocer este último la implementación de estos Protocolos en relación a que las personas solicitantes de asilo por la Frontera Sur de Estados, convino recibir a esta población y permitir la estadía en el país durante la vigencia de su trámite migratorio, lo anterior aduciendo razones humanitarias. Esta situación hizo pensar a muchos en que México se convertiría entonces en los que se denomina tercer país seguro.

¿Qué significa ser un tercer país seguro?, muchos Estados han buscado maneras de inhibir los flujos migratorios para evadir sus obligaciones de aceptar a hombres, mujeres, niñas y niños en busca de protección, organizando, para lo anterior, estrategias para que no lleguen a sus fronteras en donde, una de estas herramientas, es el reconocimiento de lo que se conoce como tercer país seguro ${ }^{1}$, término que refiere a un arreglo que le permite al país de destino reenviar a otro país (generalmente es el país de colindancia) a los solicitantes de asilo que lleguen a su territorio por considerar que éste es seguro para estos solicitantes de asilo, acuerdo que, generalmente lleva una compensación financiera. (Blenet y Carlsen, 2019).

En el caso de México, sin mediar acuerdo ni compensación financiera, a partir del 29 de enero de 2019, Estados Unidos empezó a enviar a las ciudades fronterizas a estos solicitantes de asilo para que los mismos esperaran su resolución en territorio mexicano. Si bien, como señala París (2018) un acuerdo entre México y Estados Unidos decla-

1 La práctica de tercer país seguro está vigente en la Unión Europea desde 1990 entre sus Estados miembros y desde 2013 respecto a países externos a la UE; de igual forma existe un acuerdo de tercer país seguro entre Canadá y Estados Unidos dese el año 2004 (Blenet y Carlsen, 2019). 
rando al primero como tercer país seguro, significaría que las personas de terceros países que se presenten a pedir asilo en la Frontera Sur de Estados Unidos, serían sistemáticamente rechazadas y obligadas a pedir refugio en México. En el caso del programa "Quédate en México" si bien no existió un rechazo sistemático por parte de Estados Unidos en relación con sus solicitudes de asilo, los mismos si fueron obligados a quedarse en México por todo el tiempo que durara la resolución de su situación migratoria, que, para el caso de las solicitudes de asilo de Estados Unidos, representa años de espera.

Tan solo en el año 2019, 50,000 solicitantes de asilo fueron devueltos a México, lo anterior representó para el Departamento de Seguridad Nacional de Estados Unidos (DHS) y para la Secretaría de Relaciones Exteriores de México (SRE), un suceso verdaderamente exitoso y digno de resaltar. La implementación del MPP derivó en necesidades de levantamiento de información y monitoreo en las principales ciudades mexicanas fronterizas, lo que para los Estados Unidos significó la consolidación de implementación de dispositivos de control de información para ser procesados directamente en la base de datos del ICE (Immigration and Customs Enforcement) y el Federal Boreau of Investigation (FBI), de igual forma permitió a los jueces limitar y suspender procesos de asilo político y de ciudadanía cuando lo consideraran oportuno. No obstante lo anterior, no se tomó en consideración el peligro latente que representa vivir la frontera norte de México debido a la presencia de bandas delictivas que se encuentran en la región y en donde el propio gobierno norteamericano ha advertido a sus ciudadanos evitar ciudades fronterizas como Nuevo Laredo y Matamoros. ${ }^{2}$ A pesar de lo anterior, en diciembre de 2019, precisamente fueron devueltas a estas ciudades localizadas en el Estado de Tamaulipas, 26,000 migrantes solicitantes de asilo, no obstante que este Estado está considerado en el nivel 4 de riesgo para no viajar por el U.S. State Departament, teniendo la misma evaluación de amenaza de países con regímenes enemigos, en situación de guerra o con Estados prácticamente fallidos como Libia, Afganistán e Irán (Human Rights First, 2020).

2 Un claro ejemplo de la violencia sistemática que viven los migrantes en esa región son los 19 cuerpos calcinados y con impactos de bala, hallados en una zona deshabitadada en Tamaulipas, cerca de la frontera con Estados Unidos a principios del año 2021, los mismos pertenecía a migrantes de nacionalidad guatemalteca; lo anterior no es de extrañarse si se considera que la zona está plagada de pugnas entre grupos criminales que trafican drogas, armas y por supuesto migrantes (BBC, 2021). 
El reasentamiento es definido como el traslado de refugiados de un país de asilo a otro país que ha acordado admitirles y otorgarles residencia permanente (ACNUR, 2019). En este sentido, bajo el tema de la implementación de los MPP, se puede hablar de un reasentamiento temporal o de estadía forzada, ya que los solicitantes de asilo se ven en la necesidad de esperar en México mientras sus peticiones son resueltas. Lo anterior trajo como consecuencia varios hechos: primero permitió que se continuara con la aplicación del mismo rasero político impositivo y persecutorio que ya se venía dando por décadas hacia la diáspora irregular de mexicanos radicada en Estados Unidos, con resultado igual de críticos en su momento cómo las deportaciones masivas en el periodo de Barack Obama; segundo porque ahora, las migraciones desde Centroamericana representan, en el plano político, el mismo oportunismo para profundizar las políticas de securitización y externalización de la frontera norteamericana hacia la frontera norte y sur de México.

Ni Obama ni Trump en su momento consideraron el largo expediente de violaciones a los derechos humanos por parte del Estado mexicano hacia el contingente de centroamericanos en tránsito, mucho menos cuando desde Washington se forzó a los tres países que componen el TNCA a firmar el acuerdo de tercer país seguro, un hecho insólito porque la inmensa mayoría de los migrantes forzados son oriundos de estos países. Otro repercusión estaría en el viraje de los resultados inesperados a través las acciones políticas de securitización implementadas en México que se extendería hacia las organizaciones de la sociedad civil que venían acompañando a estos migrantes en la misma ruta de tránsito, con flagrantes violaciones a los defensores de derechos humanos y con nuevas formas de criminalización hacia las acciones realizadas de forma colectiva, dejando de ser partícipes de los proyectos y acciones gubernamentales, lo anterior generaría una mayor segregación y riesgo social, tanto para migrantes como para estas organizaciones, en especial en la frontera México-estadounidense. ${ }^{3}$

De cualquier manera este fenómeno en la actualidad representa uno de los temas más controvertidos para seguir avanzando en la reconceptualización y exploración desde el plano empírico de las nuevas

3 Un claro ejemplo de lo anterior fue la detención en junio de 2019, en Hermosillo Sonora, de Irineo Mujica Arzate, líder de la organización Pueblos Sin Fronteras, la cual organizó las primeras caravanas migrantes. Su detención, de acuerdo a la Fiscalía General de la República (FGR) correspondía a una orden de aprehensión girada por el delito de tráfico de indocumentados. 
migraciones forzadas en la etapa del capitalismo neoliberal que por ahora se encuentra en un callejón sin salida en términos del tránsito migratorio al considerar el papel de países como México, países que se encuentran en otra zona gris hacia el tratamiento político de este tema. Mientras todo esto ocurre, el más lamentable de los resultados se está presentando en la realidad cotidiana de los hechos con la profundización de la crisis humanitaria y de derechos humanos que padecen las personas procedentes de Centroamérica que, a pesar de toda la atención mediática y de los cambios de gobierno en las naciones involucradas, teniendo este tema en su agenda como uno de los puntos prioritarios, no se logra resolver estos problemas, sino por el contrario, crecen cada día más en su en complejidad.

\section{Metodología}

Para cumplir con la metodología se requiriere la articulación de una explicación distinta a la unidireccional por lo cual se precisa otra explicación donde se pongan en juego múltiples determinaciones que abarque la totalidad del fenómeno en cuestión. En razón de lo anterior, el presente artículo trata de un estudio de las nuevas migraciones transnacionales centroamericanas y su nexo con los conceptos de migración forzada y geopolítica del capital regional.

El objeto de estudio es un problema teórico-empírico para los estudios de la migración internacional forzada reconstruyendo la situación de crisis humanitaria por la que atraviesa las migraciones centroamericanas en su tránsito por México mediante las medidas geoestratégicas y geopolíticas de los mecanismos de acumulación del sistema capitalista regional representado por la movilidad de una migración transnacional que ha sido despojada, excluida y violentada, pero que se mueve de acuerdo a la conformidad de los mercados laborales hacia los centros de desarrollo. Un desplazamiento que, para esta investigación, por consecuencia, es entendido como forzado a pesar de no ser reconocido como tal, lo que permite captar cierta originalidad de dicho acontecimiento en nuestro método por la dificultad del análisis teórico tradicional de las migraciones internacionales.

La investigación, al estar dentro de una perspectiva multidisciplinaria de trabajo con dimensiones que se desdoblan de acuerdo con la política migratoria de los países de tránsito y destino (México y los Estados Unidos, respectivamente) puede generar nuevo conocimiento para el estudio de las migraciones forzadas contemporáneas. En este 
sentido la estrategia en el presente texto se desenvuelve en las siguientes dimensiones:

1. Desde el plano teórico-dialéctico abordando la problemática de la migración forzada como un subproducto de la geopolítica del capitalismo, lo que da pie a reconstruir ciertos conceptos claves en el campo de las migraciones internacionales como el de migración forzada y migración en tránsito.

2. En el tratamiento de las dinámicas del capitalismo que dieron continuidad y profundización a esos mismos mecanismos de integración y reconfiguración desde el plano político de parte de las administraciones estadounidense y mexicana como es el caso de los tratados de libre comercio. De igual forma, de las medidas de seguridad y cooperación transfronteriza para toda la región que generaron como resultado el incremento en la violencia presente hacia esta migración, así como las medidas para contener la migración forzada como el MPP, programa que convirtió a México en un supuesto tercer país seguro de tránsito.

\section{LA MIGRACIÓN FORZADA DENTRO DEL CAPITALISMO NEOLIBERAL, UNA APROXIMACIÓN TEÓRICA-CONTEXTUAL}

La Organización Mundial de las Migraciones (OIM, 2019) ha definido a la migración forzada como un despazamiento migratorio en el que existe un elemento de coerción, incluidas las amenazas a la vida y los medios de subsistencia, ya sea por causas naturales o provocadas por el hombre (por ejemplo, movimientos de refugiados y desplazados internos, así como de personas desplazadas por desastres naturales o ambientales, químicos o nucleares, hambrunas o proyectos de desarrollo). Bajo esta premisa, el concepto de migración forzada dentro de los mecanismos de acumulación del capital privado encuentra un desplazamiento masivo en términos de un exilio plagado de criminalización, persecución, detenciones arbitrarias y, finalmente deportaciones para un contingente que forma parte de una fuerza laboral migrante sin posibilidad de acceder a la protección internacional.

Fuera de la legalidad o irregularidad que caracteriza este tipo de desplazamientos, existen diferentes tipos de migraciones forzadas que, aunque no se consideran como tales, sí les correspondería ese calificativo con la finalidad de seguir elevando ese reconocimiento más allá de la esfera legal, lo que apunta a tener como consecuencia que las mi- 
graciones forzadas sean producto de los mecanismos de acumulación y despojo del capitalismo neoliberal. Por ejemplo, el cuestionamiento principal, es que los desplazamientos forzados por los mecanismos de explotación capitalista desde la etapa neoliberal terminan por trazar una senda "legal" intransitable para aquellos extranjeros susceptibles a la protección internacional desde las legislaciones internacionales vigentes. Como lo señala McDowell (1995), las migraciones de carácter repentino derivadas de catástrofes naturales, u otras con un carácter más gradual como las sequias o las hambrunas, pueden atribuirse al cambio climático o a formas de violencia silenciosa por desplazamientos de megaproyectos gubernamentales o privados a gran escala producto de las economías de enclave; las presas hidroeléctricas, los planes de irrigación, la explotación de recursos naturales o la extracción intensiva por medio de la mega-minería, son un claro ejemplo de ello.

Con relación a las migraciones forzadas, Delgado y Márquez (2012) señalan que los mecanismos del desarrollo desigual generan condiciones estructurales, como el desempleo y la pobreza que catapultan las migraciones masivas de conjuntos poblacionales despojados y excluidos, señalando que las mismas poseen cuatro características en común: a). Se verifican en los planos nacional e internacional, preponderantemente desde las regiones deprimidas de las periferias con destino a regiones relativamente más avanzadas de las periferias o los centros; b). Afectan primordialmente a los sectores vulnerables, pobres y excluidos que no disponen de basamentos materiales y subjetivos para garantizar la supervivencia o alimentar una expectativa de vida decorosa; c). Generan una sobreoferta de trabajo barato y desorganizado que es aprovechada por empleadores y corporaciones interesadas en abaratar costos y; d). Alimentan los mecanismos de exportación directa e indirecta de fuerza de trabajo, poco calificado y de alta calificación.

En este contexto, al hablar de migración forzada solo se consideran los desplazamientos forzados como aquellos desplazamientos que son ocasionados por casos de violencia extrema y que atentan contra la vida de personas que pertenecen a un grupos en específico, sin embargo, esta concepción no suele abordar otras causas directamente relacionados con las migraciones transnacionales enmarcadas por condiciones distintas como las migraciones causadas por los procesos de explotación y acumulación del capitalismo, producto del desarrollo desigual, que se siguen todavía manejando como migraciones econó- 
micas, a sabiendas que este estatus no puede determinar derechos y obligaciones que impliquen, a su vez, responsabilidades de protección (Goodwin-Gill y Newland, 2003, citado en Gzesh, 2008).

Dentro del ámbito político, el reconocimiento de la migración forzada resulta igualmente complejo debido a factores propios de la dinámica del neoliberalismo contemporáneo como lo son la expansión de un conjunto de redes de capital industrial, financiero y comercial, implementadas mediante un amplio programa de reformas macroeconómicas que subordinan a los territorios involucrados con sus recursos naturales y su clase trabajadora al proyecto hegemónico del gran capital; diseñando y aplicando diversos programas, políticas e instrumentos de ajuste estructural que posibilitan la reapertura y desregularización de los flujos de inversión capitalista, de tecnología y de mercancías, una trama de acumulación tejida por las redes de capital monopolista, así mismo flexibilizando y precarizando los mercados laborales en dichas demarcaciones, los cuales forman parte estrechamente de las políticas de acumulación y despojo del capital privado provocando problemas socio-económicos acuciantes como la violencia, la falta de empleo y la pobreza extrema que motivan mayores desplazamientos de este tipo (Delgado y Márquez, 2012). Tigau (2017) corrobora esta afirmación cuando menciona que en ocasiones el capital se dirige hacia donde está la mano de obra barata o esta mano de obra barata va hacia donde se encuentran los empleos y los salarios elevados, la llamada super-explotación a domicilio. Se puede discernir sin temor alguno a equivocarse que a partir de la firma de Tratado de Libre Comercio de América del Norte (TLCAN) por Canadá, Estados Unidos y México, a mediados de la década de los 90, ocurrió la segunda variable para la población tanto de México como del Triángulo del Norte de Centroamérica (TNCA), esto es, se dieron migraciones masivas hacia Estados Unidos y en menor medida a Canadá en busca de empleos y mejores salarios al carecer de los mismos en sus ciudades de origen.

Dentro de los mismos términos políticos cuando se considera a la migración forzada de forma tradicional como los desplazamientos ocasionados por amenazas a la vida, así como los provocados por el hombre como desastres químicos, desastres nucleares o proyectos de desarrollo (OIM, 2019), suelen olvidar causas directamente relacionados con la migración transnacionales enmarcadas por condiciones distintas a la norma. En tal sentido Nair (2016) afirma que hoy en día es verdaderamente difícil poder diferenciar entre los solicitantes de asilo 
y los migrantes económicos, debido a que padecen la misma condición económica y social.

Un referente básico sigue siendo la Convención sobre el Estatuto de Refugiados concebido en 1951 y su Protocolo de 1967, este último supuestamente debería de adoptar algunas de estas circunstancias y caracterizaciones de origen para la migración forzada ya que, de acuerdo a la Convención citada la categoría de refugiado es definida de la siguiente manera:

"Toda persona que, debido a fundados temores de ser perseguida por motivos de raza, religión, nacionalidad, pertenencia a un determinado grupo social u opiniones políticas, se encuentre fuera del país de su nacionalidad y no pueda o, a causa de dichos temores, no quiera acogerse a la protección de tal país; o careciendo de nacionalidad y hallándose, a consecuencia de tales acontecimientos, fuera del país donde antes tuviera su residencia habitual, no pueda o, a causa de dichos temores, no quiera regresar a él".

Esta definición incorpora elementos dignos de análisis a tomar en cuenta en relación a quienes forman parte de las migraciones forzadas por los mecanismos del capitalismo neoliberal que siguen sin ser reconocidas como tales, por ejemplo, el hecho de encontrarse fuera del país de origen, es decir, el haber cruzado las fronteras nacionales abandonando el país al que se pertenece. De entrada dicha condición deja fuera de la protección legal a cientos de miles de desplazados internos que no han salido del país originario pero que pueden ser considerados como forzados bajo la perspectiva de la economía política de las migraciones. Otro ejemplo se puede trasladar hacia las crecientes deportaciones desde Estados Unidos de miles de trabajadores migrantes mexicanos que desafortunadamente no habían podido regular su condición migratoria y quienes sufrieron un doble rasero, forzados a irse y a regresar. Los reasentamientos temporales o estadía forzada de solicitantes de asilo es otro ejemplo claro, sobre todo para México, que ahora es considerado por su par estadounidense como supuesto tercer país seguro rompiendo con el principio internacional de non refoulement, el cual se encuentra consagrado en distintos instrumentos internacionales de Derechos Humanos tales como en la Convención Americana sobre Derechos Humanos (artículo 22.8), Convención Interamericana para Prevenir la Tortura (artículos 3 y 13) y de manera muy especial en el artículo 33 de la Convención sobre el Estatuto de los Refugiados de 1951, el cual señala que: 
“Ningún Estado contratante podrá, por expulsión o devolución, poner en modo alguno a un refugiado en las fronteras de los territorios donde su vida o su libertad peligre por causa de su raza, religión, nacionalidad, pertenencia a determinado grupo social, o de sus opiniones políticas".

De igual forma, se está dejando fuera a todas aquellas nacionalidades que utilizan México como país de tránisto con la finalidad de desplazarse hacia la frontera norte estadounidense para intentar cruzarla de forma irregular pero que de facto se encuentran en otro país que puede ser también de tránsito (más no tercer país seguro) como los países del TNCA, pero que hasta los acuerdos del MPP, a mediados del año 2019, no eran considerados como países de tránsito y donde la inmensa mayoría de los solicitantes de asilo no estaban interesados en pedir la protección internacional ${ }^{4}$. Lo anterior debido a que su principal interés era en dirigirse hacia Estados Unidos, como el centro de desarrollo capitalista que es, para poder emplear su fuerza de trabajo y ser retribuida con un salario más elevado, es decir, hay una motivación económica, sin embargo procede de haber sido "liberados" por el mismo sistema capitalista en sus comunidades de origen al privarlos de los medios básicos de subsistencia, lo que los vuelve en migrantes forzados.

El cuestionamiento principal referido es que todos estos desplazamientos forzados por los mecanismos de explotación capitalista terminan por tener un tratamiento imposible de extranjeros migrantes irregulares susceptibles a la protección internacional desde las legislaciones vigentes existentes, al otorgarles a algunos el reconocimiento de la condición de refugiados y a otros no cuando migran huyendo de las mismas situaciones de violencia o precariedad, lo que trae por consecuencia todo el espectro de violaciones a sus derechos humanos. No obstante, esto lo saben algunas organizaciones internacionales como la Asociación Internacional para el Estudio de las Migración Forzada (IASFM) que tiene una definición que contempla una situación menos restrictiva de las migraciones forzadas cuando arguye:

termino general que refiere a los movimientos de refugiados y de personas internamente desplazadas (los desplazados por conflictos), así como

$4 \quad$ Si bien la mayoría de las detenciones (presentaciones) de extranjeros que se encuentran en el país de forma irregular ante la autoridad migratoria son de personas provenientes de algún país del TNCA, también hay otras nacionalidades cuyas presentaciones sobrepasan el millar como Nicaragua, Cuba, Haití, Bangladesh, India, República Centroafricana, así como la República Democrática del Congo. 
a las personas desplazadas por desastres naturales o ambientales, desastres químicos o nucleares o proyectos de desarrollo (Gzesh, 2008).

Al igual existen otros intentos alentadores de tratar de dotar de un mejor manejo al término de migraciones forzadas inclusive desde las instituciones internacionales en materia de migración como el Alto Comisionado de las Naciones Unidas para los Refugiados (ACNUR), agencia de la Organización de las Naciones Unidas, quien con mayor información desde el Pacto Mundial de Refugiados y utilizando como referencia a los países del TNCA dentro del Marco de Respuesta Integral para los Refugiados (CRRF, por sus siglas en inglés), considera abordar a la violencia de las bandas criminales como detonante del desplazamiento forzado identificando a aquellas personas con necesidades de protección concretas y en situación de riesgo para promover un enfoque sostenible para la acción humanitaria y la asistencia para el desarrollo (Nelson-Pollard, 2017). Otro paso significativo desde la trinchera latinoamericana fue en su momento la Declaración de Cartagena sobre Refugiados, adoptada desde 1984, bajo el auspicio del mismo ACNUR, que incluía la búsqueda de soluciones no solo de los refugiados sino de los desplazados y retornados, un contexto muy presente en la región Centroamericana como parte de los acuerdos por alcanzar la paz que se desprendieron de la Conferencia Internacional sobre Refugiados Centroamericanos (CIREFCA) (Morales, 2007).

La realidad es que, mientras siga siendo beligerante la declaración vigente de la migración forzada de la Convención Sobre el Estatuto de los Refugiados de 1951 y su Protocolo de 1951, erigiéndose sobre todas las anteriores propuestas, como señala Posadas (2009), no se podrá hablar de derechos de los desplazados sino de ciertos beneficios democráticos y de ciudadanía concedidos por cualquier Estado en cuestión de ofrecer la protección de forma selectiva y muchas veces arbitraria como si únicamente se tratara de recibir estos beneficios democráticos y de ciudadanía que recibe un refugiado o beneficiario solicitante de asilo por dicho Estado que lo otorga. Cómo lo afirmaban De Genova y Peutz (2010), acerca de que estos migrantes potencialmente forzados se enfrentan a un régimen global de deportaciones que implanta dispositivos de raza y clase.

En este contexto, dentro de la problemática de la re-conceptualización de migración forzada, es necesario resaltar que el no-reconocimiento de esta migración como forzada, mediante clasificaciones migratorias como "calificada y/o altamente calificada", llega a ser lo 
que Mezzadra y Nielson (2014) llamaron una inclusión diferencial, al permitir que los Estados induzcan una regularización y organización de los ingresos de personas mediante una selección de migrantes "deseados o indeseados", en donde estos últimos han llegado a ser considerados inclusive como "ilegales" por encontrarse al margen de los citados sistemas de la migración regulada, sin importar si previamente se haya atentado o no contra su vida y sus derechos humanos, y a las migraciones "legales" como aquellas deseadas de acuerdo con los intereses desarrollistas nacionales.

Un hecho que descarta a su vez las oportunidades económicas que se puedan obtener de estos movimientos trasnacionales a través de la explotación de la fuerza de trabajo, por los cual, de forma inexorable lo que los sistemas de control de flujos de las migraciones forzadas intentan bloquear y entorpecer es el escape socioeconómico de la pobreza y el trabajo vivo desde las naciones en desarrollo periféricas (cuando este no es necesario). Quienes históricamente por sus condiciones estructurales impuestas cuentan con el tan anhelado ascenso de las clase bajas y medias, lo que implicaría obviamente una mayor vigilancia policial (Martínez y Wooding, 2017).

Es así que para Posadas (2009) el estatus de refugiado del protocolo de 1967 es un instrumento internacional de contención y para Castles y Miller (2009) un modelo eurocéntrico diseñado desde los años de la posguerra mundial para dar protección a refugiados políticos y apoyar los propósitos políticos del norte desarrollado. Estos últimos autores profundizan su argumento al argumentar que el régimen de refugiados de los países desarrollos se ha venido transformado de manera fundamental en los últimos 20 años pasando de ser un sistema diseñado para recibir a los refugiados de la Guerra Fría reasentándolos como exiliados permanentes en sus nuevos hogares hasta transformarse en un régimen de no entrada, diseñado para excluir y controlar a los solicitantes de asilo provenientes del sur periférico subdesarrollado.

El punto es que el verdadero interés humanitario de la comunidad internacional por la crisis humanitaria de los migrantes en tránsito solicitantes de asilo, esta desvirtuada y desairada puesto que las categorías dentro del sistema global de protección legal se quedan cortas ante la realidad actual. Algo que viene sucediendo de la misma forma en la Unión Europea como señala Naïr (2016) que se enfrenta a dos tipos de demanda migratoria: por un lado, está la estructural con los migrantes económicos no comunitarios y otra de tipo coyuntural 
con los solicitantes de asilo de África y Medio Oriente que huyen de situaciones de guerra. El problema que podemos observar de este lado del Atlántico en Norteamérica con las migraciones forzadas de trabajadores centroamericanos y caribeños en su mayoría, es que ambas demandas se encuentran entrelazadas, son económicas y solicitan el asilo a la vez. Una prueba más de esta contradictoria realidad se puede constatar cuando el ACNUR recibe mayoritariamente contribuciones económicas de parte de las naciones más desarrollados del norte global que cuentan con políticas abiertamente anti-inmigrantes y de contención de fronteras para la gestión masiva de las migraciones no autorizadas, como es el caso de los Estados Unidos, seguido de los 28 países miembros de la Unión Europea (Oliveira de Lima, 2017).

Las migraciones legales, deseadas y voluntarias en la actualidad ha elevado su categorización hacia la perspectiva de ser consideradas inclusive como migración "calificada o altamente calificada" retomando una perspectiva clasista que trasciende el capital humano, como mencionan Arizmendi (2011) ya que ante la expulsión de la supuesta migración no calificada de la producción económica se introduce un radical desgarramiento clasista que tiene que enfrentar el ejército de reserva del capital contra el ejército de trabajadores activos locales haciendo del primero una fuerza útil para obligar al segundo a ceder más y más, lo que estos autores califican como una "violación capitalista" de la ley del valor dentro del salario. ${ }^{5}$

Esta clasificación de migrantes "altamente calificados" puede ser comprendida como la base para la política migratoria clientelista y meritocrática que introducen las naciones conservadoras más desarrolladas al responder únicamente a lealtades políticas y a la opinión pública local, así lo considera Shachar (2006) debido a que se funda en una clasificación selectiva que apunta a que los sistemas políticos de la migración se caractericen por la competitividad, al igual es otra manera más de discriminar a las personas según sus capacidades educativas, esto último según Tannock (2011). Lo que ha llevado a una suerte de amnesia social que socava las formas en las que es entendida la inteligencia como una característica sobrevalorada que se supone

5 Respecto al factor de los salarios de los migrantes irregulares en las economías desarrolladas ver el trabajo de Emmanuel (1972), quien considera la contradicción del capitalismo acerca del factor de la producción inmóvil con el agregado de el factor móvil del trabajo, incluido sus costos comparativos como lo es salario, que para países periféricos es bajo pero con un plus-valor que no se detona hasta cuando se logra mercantilizar el mismo trabajo en las economías capitalistas desarrolladas, por lo cual la migración no corresponde a ningún tipo de racionalidad ni de progreso para las naciones pobres. 
radica dentro de las personas para seguir justificando las desigualdades sociales asociado a discursos de racionalidad y habilidades, esto otro según Bhavnani (1994). Otra consecuencia bastante más perniciosa de retomar esta categorización hacia la perspectiva de ser consideradas como "altamente calificadas" dentro de la perspectiva clasista que intenta trascender las habilidades y el capital humano es que se aumentan los temores exagerados hacia los trabajadores poco calificados acerca de su supuesta incidencia en el crimen, como dice Canternbury (2012).

Además, que con este tipo de categorizaciones acontece un efecto que cada vez se está normalizando para las economías periféricas como México; el que formen parte de otro mecanismo de primarización de la producción local cuando cada vez afluye más capital social de trabajadores calificados de estas naciones hacia el norte, desde el mundo pobre al mundo rico, en lugar de que fuera al revés como pareciera ser más necesario, infiere Reinret (2007). Inclusive la Comisión Mundial sobre las Migraciones Internacionales (GCIM) hizo énfasis en su informe de 2005 sobre la distinción típica entre empleados calificados y no calificados arguyendo que no ayuda en mucho a hacerle justicia a este asunto de gran complejidad dentro de las migraciones internacionales, se mencionaba que aun existiendo diferencias en los niveles educativos todos ellos pueden ser descritos como trabajadores legítimos y esenciales (Khadria y Meyer, 2012).

Por consecuencia Naïr (2016) refiere acerca de que emigrar legalmente se ha convertido en un auténtico lujo no así para los que emigran "ilegalmente" pues para ellos las puertas que logran evadir se convertirán en un infierno penal y burocrático que puede conducir a la muerte. El problema hasta aquí de seguir considerando a los desplazamientos humanos como el caso de las personas proveniente del TNCA devueltos al tránsito por México por razones de una supuesta libre elección económica y/o voluntaria junto con sus supuestas bajas calificaciones y no bajo el rasero de la migración forzada legal es creer que estos movimientos son ajenos a los mecanismos del desarrollo desigual del capitalismo neoliberal para toda la región centroamericana y que las causas se pueden encontrar en otras cuestiones ajenas al despojo y la explotación económica que se padece crónicamente en estos lugares de origen.

Para cerrar este apartado retomando a Naïr (2016), este autor teme que este nuevo tránsito forzado presente en varias latitudes del 
planeta conlleve el riesgo de quebrar el consenso universal de mínimos alcanzados por la Convención de Ginebra de 1951 y su Protocolo respecto a lo que se debe de entender por "refugiado" por ello añade debe de ser mucho más adecuada otra interpretación de la Convención por parte de los Estados involucrados en especial los de tránsito, una que dé cabida a la situación de los nuevos refugiados que carecen de protección internacional conforme al estatuto legal. Este autor señala que se debe de destacar ante todo la potencialidad de la obligación del principio de non refoulement (no devolución) como principio de derecho internacional general, un valioso instrumento que, como se ha visto, está siendo descartado a la hora de proteger la situación de los solicitantes de asilo.

\section{LA ORBITA GEOPOLÍTICA DE LAS MIGRACIONES FORZADAS EN TRÁNSITO}

El tránsito migratorio, como un punto intermedio que ocasionalmente se encuentra en condiciones inciertas e inseguras dentro de una órbita de transito alrededor del mundo, inexorablemente trae a cuenta la denominada "migración ilegal o indocumentada" como una condición de irregularidad que predispone a la noción de "país de tránsito" que, en realidad, es una condición de circularidad prolongada, tal como refiere Marconi (2008) no solo resulta casi imposible determinar el límite entre tránsito e inmigración indocumentada, sino que desafortunadamente el término "migración de tránsito" se ha convertido en un código para señalar a la misma inmigración indocumentada.

Esta migración en tránsito no conoce fronteras, a pesar de la restricción de las mismas en esta etapa del capitalismo neoliberal, porque se extiende más allá de las migraciones forzadas centroamericanas por México. Esta realidad internacional trasciende aún más cuando este éxodo humano forma parte de una tercera parte de los 200 millones de migrantes internacionales que existen en la actualidad, los que se mudaron de un país en desarrollo a otro desarrollado, es decir, alrededor de 70 millones, de los que se estima cerca de 14 millones son desplazamientos forzados por problemas de seguridad o conflictos internos (PNUD, 2009, citado en Canternbury, 2012).

En relación a las crisis de las migraciones dentro de los países de tránsito, las mismas han recrudecido el debate, como es el caso tan marcado de México, del término común de "país de tránsito" en función de las migraciones transnacionales no autorizadas y devoluciones 
de solicitantes de asilo. Tema de trascendencia porque se han convertido en un punto de inflexión y a la vez neurálgico de las estas nuevas migraciones forzadas, inclusive en un aspecto paradigmático de la nueva dialéctica hacia el estudio de las migraciones internacionales aunque, como señala el Alto Comisionado de las Naciones Unidas para los Derechos Humanos (2016) no haya una definición "canónica" del concepto de tránsito en el que se destaca la temporalidad, entendido el mismo como una estancia temporal de los migrantes en uno o varios países con el objetivo de llegar a otro. En este sentido, los países de tránsito constituyen una suerte de "órbita geopolítica" representando uno de los desafíos más importantes de la movilidad internacional y de las políticas públicas hacia la migración forzada. En este sentido, Papadopulou (2005) señala que a migración en tránsito es simplemente el estadio entre emigración y establecimiento. Sin embargo, la realidad es más compleja, como lo señala Marconi (2008) al manifestar que jurídicamente hablando, el tránsito debería ser temporal y limitado pero, en la práctica, puede terminar siendo de largo plazo y semipermanente porque hay siempre más obstáculos - principalmente de naturaleza económica y/o política - que obligan a muchos migrantes a pararse prolongadamente en algún lugar durante su viaje, sin perspectivas reales inmediatas de alcanzar su meta ni tampoco de volver a su lugar de origen.

Es así que un país de tránsito se define principalmente por la dinámica de los flujos migratorios, siendo los más importantes su contención, aunado a la política, jurisdicción y temporalidad. Es decir, como apunta la misma Marconi (2008) acerca de los países de tránsito que son casi exclusivamente los que colindan con los países ricos y cita como ejemplo el caso salvadoreño, hondureño o nicaraguense, una buena parte de las nacionalidades que atraviesan México para llegar a Estados Unidos y que anteriormente cruzaron por territorios pertenecientes a naciones que no son consideradas como naciones de tránsito pero que en la práctica lo son, como es el caso de Guatemala, ya que en este sistema migratorio el espacio de tránsito por tradición y antonomasia le corresponde a México, más aún al haber permitido implementar la política estadounidense a través de estas estadías forzadas de peticionarios de asilo mediante el programa "quédate en casa", en gran parte por la magnitud y evolución de sus patrones migratorios y por la enorme frontera que comparte con Estados Unidos. 


\section{MÉXICO COMO “TERCER PAÍS SEGURO" CONSIDERACIONES A PARTIR DE LA CRISIS HUMANITARIA Y DE DERECHOS HUMANOS DE LAS MIGRACIONES FORZADAS CENTROAMERICANAS}

Las migraciones masivas de mexicanos acontecidas durante décadas así como las recientes migraciones centroamericanos hacia Estados Unidos, han sido permeadas por la irregularidad y la falta de documentación, debido, en gran medida, a los dispositivos legales producto de los citados ajustes a los mercados del capital neoliberal. Inclusive, se puede señalar que de forma paralela hay otras formas de ver estas "crisis migratorias" que justificaron medidas como el MPP. ${ }^{6}$ Una de estas medidas es la que dio sustento y continuidad a las acciones políticas de la construcción del muro fronterizo durante el mandato presidencial de Donald Trump, medida declarada como una "emergencia nacional" durante su administración. Lo que en dado caso lleva a contemplar que, lo que en realidad se presenta, es una crisis en relación a las políticas migratorias más que una crisis en sí de la migración forzada. Lo que sostiene el argumento de que la debilidad del concepto crisis civilizatoria o humanitaria, para las migraciones, reside justo y ante todo en que desliza determinismo histórico (Arizmendi, 2011: 181). Alcaide (2016) preveía de antemano el uso indebido de la expresión "crisis humanitaria", para hablar de las migraciones forzadas por las connotaciones negativas y tremendistas de la palabra y porque dice responsabiliza a las personas que intentan buscar refugio y no ponen el acento en las políticas migratorias que las provocaron.

La situación del reasentamiento temporal de solicitantes de asilo bajo los MPP, a los que se les puede calificar de migrantes forzados, pone en predicamentos a las instituciones mexicanas en materia de migración como el Instituto Nacional de Migración (INM) y la Comisión de Ayuda al Refugiado (COMAR), quienes históricamente han poseído una estructura insuficiente para resolver de manera eficas estos problemas. La primera, debido a las órdenes del actual gobierno (4T) en relación a frenar los contingentes migratorios que arriben al país, se encuentra en el ojo del huracán en medio de controversias por las constantes extorsiones y los malos tratos de sus funcionarios hacia los migrantes, en especial en la frontera sur; la segunda, que tiene por mi-

6 El término crisis migratoria describe los flujos migratorios complejos y generalmente a gran escala, así como los patrones de movilidad ocasionados por una crisis que suelen traer consigo considerables vulnerabilidades para las personas y comunidades afectadas, y plantear serios retos de gestión de la migración a más largo plazo (OIM, 2016). 
sión estudiar las peticiones de asilo, presenta una crónica tardanza burocrática y una política de disuasión de un gran número de peticiones de refugio, terminando por negar la mayoría de los casos, situación ha ido poco a poco colapsando el sistema de refugio en México.

Un ejemplo de lo anterior son las cifras presentadas por la Comisión de Ayuda al Refugiado (COMAR) en donde señala que, en el año 2013, se recibieron 1,296 solicitudes para el reconocimiento de la condición de refugio, una cifra que aumentaría de forma extraordinaria para el año 2018 con un total de 29,648 solicitantes de asilo, esto significó que en tan solo cinco años hubo un incremento de 2,287 por ciento de peticionarios de refugio. Con la llegada de las caravanas migrantes y la implementación del programa MPP, acorde a datos de la COMAR (2019), entre los años 2019 y 2020 se presentaron ante dicha dependencia 111,839 solicitudes de la condición de refugiado. ${ }^{7}$

Bajo esta tesitura, con relación a los peticionarios de asilo y acorde a la definición de tercer país seguro, un Estado receptor de migrantes debe tener garantizado un estandar mínimo de protección hacia los derechos humanos de las personas bajo su jurisdicción, como son los solicitantes de asilo. Es evidente que, respecto a la seguridad, México no califica como tal para brindar condiciones mínimas de respeto y garantía de derechos hacia los solicitantes de asilo reasentados temporalmente en la frontera norte, México es un espacio que incrementa los riesgos para todos los migrantes irregulares, para cualquiera que haya atravesado este vasto territorio de forma irregular se presenta un doblegado tránsito en donde aparece junto al desmantelamiento de los derechos sociales y políticos del ser "indocumentado" otra suerte de deshumanización mediante el rompimiento de los principios básicos de toda dignidad humana. Puede ser entendida como la vida desnuda que citaba Agamben (2017) cuando se despoja de todos los derechos inherentes como ser humano, ya que a lo largo de este tránsito forzado se forma una línea divisoria de lo humano y no humano, un abismo igualmente pernicioso entre otra zona del ser y del no-ser moderno. Así de grande puede ser la inferiorización de ciertos grupos humanos en un mundo de relaciones neocoloniales del capitalismo, así de grande es la línea abismal que señala Boaventura Dos Santos (2014).

7 Dentro de este período de tiempo Honduras es el país con más solicitantes de refugio en México con un total de 45,627, seguido por Cuba con 14,460 solicitudes y en tercer y cuarto lugar se encuentran El Salvador con 13,059 y Hatí con 11,488 solicitudes, respectivamente (COMAR, 2019). 
En gran medida, la situación que presenta México como un país en donde los derechos de las personas en contexto de movilidad son violentados y su seguridad, mientras transitan por territorio mexicano, no está garantizada, deviene de la paulatina transición de la política migratoria mexicana, la cual actualmente se encuentra en la disyuntiva de contener la migración irregular al mismo tiempo que respeta sus derechos humanos. Fue a partir del año 2001, con el ataque a las torres gemelas en Nueva York en septiembre de ese año, donde se intensificaría el concepto de seguridad implementado al tema migratorio, ya que, a raíz de este hecho, el Estado Mexicano implementó programas enfocados a la contención de la migración tales como el Plan Frontera Sur, encaminado a la contención y al control de la migración en tránsito, así como el Plan de Acción entre Mexico y Estados Unidos para la cooperación sobre seguridad fronteriza (Anguiano y Lucero, 2020). De ahí vendrían otros acuerdos que tendrían como finalidad "regular" la movilidad fronteriza, cuando en realidad lo que se buscaba era limitar el desplazamiento de migrantes irregulares por territorio mexicano. Esta política por parte de las autoridades mexicanas, aunado a la los sentimientos de xenofobia y el racismo que permean en una gran parte del país, desataría una ola de violencia inusitada en contra de los migrantes centroamericanos en contexto de movilidad, violencia que limitaría ante todo, el proyecto de vida de estas personas, especialmente cuando las tradicionales rutas del tráfico de la droga de los carteles coincidirían con las rutas de la migración irregular, en especial la del Golfo de México, las cuales se encargan de regular el tránsito de estos migrantes centroamericanos mediante la trata y el tráfico de personas. La máxima expresión de esta violencia a través de la vida desnuda-inferiorización-deshumanización hacia el migrante centroamericano en tránsito por México se presentaría en agosto de 2010 con el hecho más insólito y vehemente hasta ahora en el tránsito mexicano cuando en el municipio de San Fernando, en el estado fronterizo de Tamaulipas, 72 inmigrantes fueron asesinados a manos del crimen organizado, en específico por el grupo criminal Los Zetas que operan y controlaban la región del Golfo de México. La razón por la que los privaron de la vida fue porque nos les entregaron el dinero exigido, es decir, no pudieron pagar rescate.

Este hecho lamentable se dio a pesar de que un año antes la Comisión Nacional de los Derechos Humanos (CNDH) en su informe especial sobre casos de secuestros de migrantes, había visibilizado la 
preocupante situación que experimentaban las personas en contexto de movilidad al señalar que durante septiembre de 2008 a febrero de 2009, alrededor de 9,758 personas habían sido víctimas de secuestro durante su paso por México por bandas pertenecientes a la delincuencia organizada e inclusive por las autoridades gubernamentales, secuestro que les habían generado una ganancia de 25 millones de dólares en rescates y en donde la gran mayoría de las personas secuestradas provenían de alguno de los países del TNCA (CNDH, 2009). El informe también señala que se había incrementado, en gran medida, debido a que México no ha logrado implementar una estrategia que ordene todo este tránsito transfronterizo sino todo lo contrario los métodos implementados han sido los causantes de más violaciones a los derechos humanos similares a los que México denuncia a los Estados Unidos en su trato a nuestros connacionales.

Quizá, por el peligro que representa México para los migrantes en tránsito en situación migratoria irregular, es que los mismos decidieron organizarce y migrar en Caravanas, como una forma de protección a estos peligros del viaje. Las primeras caravanas de migrantes que transitaron por México a fines de 2018, tenían la finalidad de llegar hasta la ciudad fronteriza de Tijuana, colindante con el Estado de California, utilizando la denomina ruta del Pacifico, la más larga con relación a la ruta del golfo. Si bien en su paso por la Ciudad de México se encontrarían con ciertas muestras de apoyo por parte del gobierno entrante de la Ciudad de México, el cual montó un operativo de asistencia en conjunto con organizaciones civiles y gubernamentales para facilitar su libre tránsito, donde encontrarían por parte de la población local amplias muestras de odio, rechazo, nacionalismo y xenofobia sería en la frontera norte, específicamente en Tijuana. Lo anterior sorprendió a muchos ya que esta ciudad tiene fama de ser una ciudad hospitalaria con los migrantes prueba de ello es lo bien que están integrados a la comunidad la migración haitiana como prueba que si pueden coexistir dos nacionalidades distintas en un mismo territorio. Sin embargo, las caravanas de migrantes conformadas en su mayoría por población del TNCA, no fueron bien recibidas en esta localidad en donde los participantes de estas caravanas fueron confinados en varios albergues temporales cercanos a "la línea", hasta que las autoridades de migración decidieron instalarlos en lo que bien se podría considerar como uno de los primeros "campos de refugiados" en México, por el fuerte cerco de seguridad en "El Barretal", un antiguo mercado y centro de espec- 
táculos a decenas de kilómetros lejos de la frontera en donde estos migrantes fueron alojados.

La segunda caravana de migrantes centroamericanos, tan solo un par de meses después, tomaría la otra tradicional ruta de tránsito, la del centro, con la finalidad de llegar a Piedras Negras, Coahuila, ciudad fronteriza con el estado de Texas. Al igual que su antecesora, esta segunda caravana trataría de cruzar hacia los Estados Unidos con la misma intención de solicitar la protección internacional, esta vez por el célebre Rio Bravo, para también toparse con la misma mala fortuna de tener un trato despótico y amenazante por parte de la población local, lo que llevaría a las autoridades a consolidar la misma estrategia de seguridad montando un nuevo "campo de refugiados" fronterizo.

Este viaje en caravanas para protegerse de los peligros, y como forma de visibilizarse hacia sus peticiones de solicitud de asilo en Estados Unidos, no les valió de mucho ya que a raíz de la implementación por parte de Estados Unidos de los MPP, estas poblaciones quedaron baradas en México mientras esperaban sus resoluciones de asilo, en un ambiente precario en donde el gobierno se limitó a dar visas humanitarias para regular la situación migratoria de estas personas mientras esperaban sus resoluciones de asilo, pero no se avocó a realmente satisfacer los derechos básicos de esta población (vivienda, trabajo, educación, etcétera) y donde se sumaría el endurecimiento de los trámites de asilo por parte de Estados Unidos. Un ejemplo de lo anterior fue la orden emitida por el entonces Fiscal Federal de los Estados Jeff Sessions, en el año 2018, la cual instruía a los jueces de inmigración a rechazar las peticiones de asilo de aquellos inmigrantes que arguyeran que habían experimentado violencia a mano de las pandillas o habían vivido violencia doméstica en los lugares de origen, lo anterior por considerar que se trataba de "delitos privados" que no eran motivo para otorgar el beneficio de asilo (García, 2018). Todas estas situaciones no hicieron mas que acrecentar la dificil situación que vivían los solicitantes de asilo en su estadía en México, el cual, debería de ser un lugar "seguro", sin embargo, con el paso del tiempo, se volvía un lugar sumamente peligroso para la población migrante en espera de sus resoluciones de asilo. A lo anterior se sumaría la angustia de que, muy probablemente, sus peticiones fueran rechazadas, lo que los llevaría a plantearse quedarse en México de forma permanente. 


\section{ConCLUSIón}

Una reconceptualización de la migración forzada puede llevar a conclusiones que contraponen a la tradicional migración voluntaria o económica como una decisión supuestamente libre, en específico es una condición que permite entender a las migraciones del capitalismo por acumulación y despojo como forzadas. Pero mientras esto sucede y se eleve el reconocimiento y tratamiento de estos desplazamientos en términos formales a migración forzada, lo que podemos encontrar en el tránsito migratorio mexicano son migraciones, pero sin refugiados, puesto que la condición de refugiado siempre debe de ser precedida por un desplazamiento forzado.

De la misma forma, esta situación representa un reto en términos teóricos hacia el tratamiento de las migraciones forzadas, debido a que este término se ha sido utilizado únicamente como un mecanismo legal de selección de migrantes "buenos" y "calificados" en función de los intereses desarrollistas de las naciones del primer mundo, quienes inclusive, como el caso de los Estados Unidos para la región de Centroamérica está directamente relacionado con la generación y procreación de este éxodo migratorio desde sus orígenes, ya sea por los mecanismos de integración y reconfiguración de los mercados locales laborales del capitalismo, acompañado por las intervenciones militares, todo lo cual creó el caldo de cultivo para la violencia generalizada que se vive al interior de las comunidades de origen.

En términos empíricos para el Estado mexicano la crítica está dirigida hacia la condición de doble moral de haber firmado la mayoría de los instrumentos internacionales en materia de derechos humanos, estos derechos consagrados independientemente del mandato constitucional tienen que ser respetados y garantizados a toda persona bajo su jurisdicción, sin distinción alguna y con independencia de su estatus migratorio, pero existe otro realidad alternativa, como afirma Riccardi (2017) acerca de cuándo las migraciones se convierten en un problema político, para ese momento, se está obligado por parte del Estado a redefinir sus funciones. Si bien, en este contexto los Estados tienen todo el derecho soberano de decidir quién entra y no, a su territorio y por lo anterior adoptar medidas relativas a la migración y a la seguridad de sus fronteras, también deben de cumplir con las obligaciones que les impone el derecho internacional con relación a los derechos humanos de los migrantes sin discriminación de ningún tipo, prestan- 
do asistencia a los migrantes que lo necesiten con independencia de su situación migratoria y, a la par, crear un entorno seguro y propicio para que las personas y organizaciones que presten ayuda a este grupo en particular lo hagan sin obstáculos y en un ambiente seguro (UNGA, 2015). Una situación que con los reasentados por el MPP no se cumple porque no se respeta el principio de no devolución o non refoulement, que forma parte del derecho internacional al prohibir a cualquier país que recibe refugiados devolverlos a un país en donde correrán los mismos riesgos que los llevó a solicitar el asilo.

La supuesta descarga que representaría México para los Estados Unidos a través de la vía del supuesto tercer país seguro no es equitativa ni éticamente correcta, es devolver y reasentar a los peticionarios de asilo de vuelta a las persecuciones y amenazas de la que venían huyendo desde el origen y que desafortudamente se agravó durante el tránsito migratorio por el territorio mexicano. Además de relativizar aún más el concepto de protección internacional de la migración forzada violando los términos de non refoulement expuestos en la Convención sobre Refugiados de 1951 puesto que no se garantiza en este especifico caso el acceso a la residencia, ni al mercado laboral, ni mucho menos a los servicios médicos o educativos y al desentendido derecho de reunificación familiar, todo lo contrario se sigue fomentando más migración irregular a través de las fronteras con estas medidas.

A raíz de todo lo anterior, estuvo presente en este trabajo de manera subrepticia la disyuntiva entre si esta es una crisis humanitaria o una crisis política y de derechos humanos. un tratamiento que considera lo dicho por el entonces presidente de Estados Unidos Donald J. Trump, quien valiéndose de esta coyuntura ha promovido políticas de corte restrictivo mediante órdenes ejecutivas para frenar la migración desde Centroamérica y de paso desde México también, lo que motiva a su vez las devoluciones de peticionarios de asilo violando las legislaciones existentes, profundizando la verdadera crisis de derechos humanos de estas migraciones forzadas, sin el reconocimiento a pesar de serlo por los mecanismos de integración de los mercados laborales del sistema capitalista en Norteamérica.

Por todo lo anterior, se intentó desmontar las actuales medidas del gobierno norteamericano con relación a considerar a México como supuesto tercer país seguro de las devoluciones de solicitantes de asilo, a partir del largo historial de violaciones a los derechos humanos de las migraciones consideradas como irregulares en tránsito por el territo- 
rio mexicano, desde la descomposición de las instituciones mexicanas en materia de migración permeadas por la corrupción y la ineficacia burocrática, así como por la red de tráfico de personas por parte de la delincuencia organizada que opera por las tradicionales rutas de la migración irregular a lo largo de México; de igual forma, como el hecho de que México no puede ser un filtro para Estados Unidos ni prestarse a recibir migrantes con procedimientos de asilo abiertos en aquél país, siendo lo anterior una clara violación al derecho al asilo.

En este entendido son lamentables los hechos de negligencia política en el tema de la migración forzada como bien señala Djordjevch (1961) al afirmar que la historia muestra como un pueblo se condena a sí mismo al bloqueo ideológico haciéndolo en detrimento de su democracia interna y de las libertades de sus ciudadanos.

Esto cuadra en nuestro análisis porque en la medida en que se restrinjan las libertades de los migrantes en tránsito por México y rumbo hacia Estados Unidos, se estarán restringiendo a su vez las libertades de los ciudadanos mexicanos, en especial de las clases trabajadores, debido a que ambos grupos de ciudadanos pertenecen a la misma clase proletarizada creada bajos los mismos procesos y mecanismo de explotación y exclusión del capitalismo neoliberal, una clase que históricamente han recibido el mismo trato despótico de parte de Estados Unidos. Así, lo que se está restringiendo más allá de la migración forzada, son los derechos del ciudadano, que son aquellos derechos fundamentales del hombre que no pueden ser ejercidos mientras una clase pueda asegurarse un sustento por el trabajo de otra clase, privando a estas clases subordinadas de los medios elementales de subsistencia (Djordjevch, 1961). Es decir, en términos más claros con nuestro estudio de caso, lo que los gobiernos de México han estado preservando y cuidando, paradójicamente son los medios de producción de la sociedad capitalista estadounidense, quienes se han apropiado del producto social creado por el trabajo y quienes gozan de la tasa de plusvalía producto del mismo trabajo asalariado en condiciones de irregularidad, inseguridad y explotación.

Es importante comprender esta situación para saber lo que les depara a los miles de migrantes en tránsito que se siguen integrando a las múltiples caravanas que se siguen organizando con la intención de llegar a la frontera norte de México, ya sea que decidan quedarse en México con la posibilidad de regularizar su situación migratoria, o, por 
el contrario, decidan solicitar el asilo en los Estados Unidos, su panorama se ve poco favorecedor.

Así, la migración centroamericana enfrenta, por lo pronto, fuertes barreras institucionales debido a que los mismos, conforme al concepto actual de migración forzada, no son considerados como tal a pesar de que su migración es, de facto, una migración forzada, de ahí la imperiosa necesidad de re-conceptualizar esta migración creando nuevas definiciones que consideren a las personas que han huido de estos países debido a los mecanismos de desarrollo desigual y del despojo propulsado por el capitalismo neoliberal de acumulación en virtud de que la vida, seguridad y libertad, están siendo igualmente amenazadas por la violencia generalizada que deriva de estos procesos.

\section{REFERENCIAS BIBLIOGRÁFICAS}

Alto Comisionado de las Naciones Unidas para los Derechos Humanos (ACNUDH). (2016). Situación de los migrantes en tránsito. Informe de la Oficina del Alto Comisionado de las Naciones Unidas para los Derechos Humanos. Disponible en https://www.acnur.org/fileadmin/Documentos/BDL/2016/10356.pdf

Alto Comisionado de las Naciones Unidas para los Refugiados (ACNUR). (2019). Resantamiento. Disponible en https://www.acnur.org/reasentamiento.html

Agamben, G. (2017). Homo Sacer. El poder soberano y la vida desnuda. Argentina: Adriana Hidalgo Editora.

Alcaide, X. (2016). "Porque la crisis de los refugiados no es una crisis de refugiados", en Por la paz/peace in progress. Núm. 29.

Anguiano, M.E. y C. Lucero (2020). "La construcción gradual de la política de contención migratoria en México", en Villafuerte D. y M.E. Anguiano (Coords.). Movilidad humana en tránsito: retos de la cuarta transformación en política migratoria. México: UNICACH, CESMECA y CLACSO.

Arizmendi, L. (2011). "Crisis épocal del Capitalismo y desmencantificación en el Siglo XXI", en Horizontes de la vuelta de siglo. México: Arizmendi.

Asamblea General de las Naciones Unidas (UNGA) (2015). Protección de los derechos humanos de los migrantes: migrantes en tránsito. Consejo de Derechos Humanos. Disponible en https://www.acnur.org/fileadmin/ Documentos/BDL/2015/10161.pdf

Bhavnani, K. K. (1994). "Shifting the subject: A conversation between Kum-Kum Bhavnani and Donna Haraway", in Feminism \& Psychology: an International Journal, Santa Cruz, California, No, 4, pp,19-39. 
Blenet, A. y L. Carlsen. (2019). México y el acuerdo de Tercer País Seguro. Negación del derecho de asilo y externalización de Fronteras. Programa de las Américas. Disponible en https://www.americas.org/informe-mexicoy-el-acuerdo-de-tercer-pais-seguro/

Boaventura de Sousa, S. (2014). Si Dios fuese activista de los derechos humanos. Madrid: Trotta.

British Broadcasting Corporation (BBC) (2021). Tamaulipas: hallan calcinados los cuerpos de 19 personas asesinadas en el noreste de México. Disponible en https://www.bbc.com/mundo/noticias-america-latina-55791419

Canternbury, C. D. (2012). "Impacto de la migración en el desarrollo bajo el capitalismo neoliberal", en Desarrollo desigual y migración forzada. Una mirada desde el sur global. Delgado, R. y H. Márquez (coords.). México: Universidad Autónoma de Zacatecas y Miguel Ángel Porrúa Editores. p. 109-139.

Castles, S. y M. Miller (2009). La era de la migración. Movimientos internacionales de la población en el mundo moderno. México: Miguel Ángel Porrúa Editores.

Comisión de Ayuda al Refugio (COMAR) (2019). Reporte de Junio. Disponible en https://www.gob.mx/cms/uploads/attachment/file/473300/ REPORTE_CIERRE_DE_JUNIO_2019.pdf

Comisión Nacional de Derechos Humanos (CNDH) (2009). Informe Especial Sobre los Casos de Secuestros en Contra de Migrantes. Disponible en https://www.cndh.org.mx/documento/informe-especial-sobre-los-casos-de-secuestro-en-contra-de-migrantes

Convención Americana de Derechos Humanos suscrita en la Conferencia Especializada Interamericana Sobre Derechos Humanos. San José, Costa Rica, 22 de noviembre de 1969.

Convención Interamericana para Prevenir y Sancionar la Tortura. Cartagena de Indias, Colombia, 9 de diciembre de 1985.

Convención Sobre el Estatuto de los Refugiados. Ginebra, Suiza, 28 de julio de 1951.

De Genova, N. y N. Peutz. (2010). The deportation regime: sovereignty, space and freedom of movement. New York: Duke University Press.

Delgado, R. y H. Márquez (2012). “Una perspectiva del sur global, migración forzado y desarrollo desigual”, en Delgado, R. y H. Márquez (coords.), Desarrollo desigual y migración forzada. Una mirada desde el sur global. México: Universidad Autónoma de Zacatecas y Miguel Ángel Porrúa. México, p. 13-42.

Djordjevch, J. (1961). Yugoslavia, democracia socialista. México. Fondo de Cultura Económica. 
Emmanuel, A. (1972). Unequal Exchange. A Study of the Imperialism of Trade. New York and London. Monthly Review Press.

García, J. (2018). Jeff Session ordena negar asilo a inmigrantes víctimas de pandillas y violencia doméstica. México: El Diario. Disponible en https:// eldiariony.com/2018/06/11/jeff-sessions-ordena-negar-asilo-a-inmigrantes-victimas-de-pandillas-y-violencia-domestica/

Gzesh, S. (2008). “Una redefinición de la migración forzada con base en los derechos humanos", en Revista Migración y Desarrollo. Vol. 10. p. 97-126.

Human Rights First (2020). A year of horrors: the Trump administration's illegal returns of asylum seekers to danger in Mexico. Disponible en https://www.humanrightsfirst.org/resource/year-horrors-trump-administration-s-illegal-returns-asylum-seekers-danger-mexico

Khadria, B. y J.B. Meyer (2012). “El papel de la migración en la restructuración de los sistemas de innovación”, en Delgado, R. y H. Márquez (coords.), Desarrollo desigual y migración forzada. Una mirada desde el sur global. México: Universidad Autónoma de Zacatecas y Miguel Ángel Porrúa. p. 145-175.

Marconi, G. (2008). "Ciudades de tránsito, guardianes del primer mundo. Entre desafíos, contradicciones y compromisos", en VI Encuentro anual de RedGob. Lisboa. Disponible en http://campus.usal.es/ redgob/papers2008/marconi\%20-\%20redgob\%202008.pdf

Martínez, S. y B. Wooding (2017). "El antihaitianismo en la Republica Dominicana: ¿un giro biopolítico?", en Revista Migración y Desarrollo. Núm. 28. p. 95-124.

McDowel, C. (1995). "Development-Induced Displacement", en The Courier Africa-Caribbean-Pacific/European Community. Núm.150, marzo-abril. Bruselas. p. 56-57.

Mezzadra, S. y B. Nielson (2014). "Fronteras de inclusión diferencial. Subjetividad y luchas en el umbral de los excesos de justicia", en Papeles del CEIC, vol. 2014/2, núm. 113, CEIC (Centro de Estudios sobre la Identidad Colectiva), Universidad del País Vasco. Disponible en: http://dx.doi. org/10.1387/pceic.12980

Morales, A. (2007). La diáspora de la posguerra. Regionalismos de los migrantes y dinámicas territoriales en América Central. Costa Rica: FLACSO. p.45.

Naïr, S. (2016). Refugiados frente a la catástrofe humanitaria, una solución real. Barcelona: Editorial Planeta. p. 67.

Nelson-Pollard, S. (2017). "La violencia criminal en Honduras como detonante del desplazamiento", en Revista Migraciones Forzadas. Núm. 56. p. 14-18.

Oliveira de Lima, G. (2017). "De la violencia biopolítica a la política de extranjería: el desafío de los derechos humanos por venir en el pensamiento 
de Jacques Derrida", en Bernardo Bolaños (coord.). Biopolítica y migración. El eslabón perdido de la globalización. México: UAM-Cuajimalpa.

Organización Mundial de las Migraciones (OIM) (2019). Glosary on Migration. Disponible en: https://publications.iom.int/system/files/pdf/ iml_34_glossary.pdf

Organización Mundial de las Migraciones (OIM) (2016). Qué es una crisis migratoria y como atenderla integralmente. Disponible en https://rosanjose.iom.int/site/es/blog/que-es-una-crisis-migratoria-y-como-atenderla-integralmente

Papadopulou, A. (2005). "Exploring the asylum-migration nexus: a case study of transit migrants in Europe", in Global Migration Perspectives. Genova: Global Comission on International Migration. No. 23.

París, D. (2018). Qué significa el programa "Quédate en México" y en qué difiere de "México como tercer país seguro". Disponible en https://www. colef.mx/noticia/que-significa-el-programa-quedate-en-mexico-y-enque-difiere-de-mexico-como-tercer-pais-seguro/

Protocolo Sobre el Estatuto de los Refugiados. Nueva York, Estados Unidos de América, 31 de enero 1967.

Posadas, P. (2009). "Refugiados y desplazados forzados. Categorías de la migración forzada creadas como medidas de contención a las migraciones no deseadas", en Estudios Políticos. Universidad de Antioquia. Núm. 35. p. 131-152.

Reinret, E. (2007). La globalización de la pobreza. Como se enriquecieron los países ricos... y por qué los países pobres siguen siendo pobres. España: Grupo Planeta. p.78

Ricciardi, M. (2017). “Migrantes, poder y capital. Acerca de la teoría política de las migraciones", en Olvera García et al. (coord.) Migración y trabajo en el capitalismo global. México: Gedisa.

Shachar, A. (2006). "The race for talent: highly skilled migrants and competitive immigration regimes", in New York University Law Review. Universidad de Toronto. Núm. 81. p. 148-206.

Tannock, S. (2011). "Points of perjuice: educatios-based discrimination in Canada's inmigration system", in Antipode. vol. 43. núm. 4. p. 1330-1356.

Tigau, C. (2017). "Migrantes "buenos" y "malos": biopolíticas de selección de trabajadores extranjeros en América del norte", en Bernardo Bolaños (coord.). Biopolítica y migración. El eslabón perdido de la globalización. México: UAM-Cuajimalpa. p. 98. 


\section{RESUMEN CURRICULAR DE LOS AUTORES}

Jorge Morales Cardiel

Doctorante en el Doctorado en Estudios del Desarrollo por la Universidad Autónoma de Zacatecas, Maestro en Desarrollo Local y Territorio y licenciado en Geografía y ordenación territorial, ambas por la Universidad de Guadalajara, México (UdeG). Máster en Migraciones Internacionales, Investigación, Políticas Migratorias y Mediación Intercultural, por la Universidad de A Coruña (UDC), España. Entre sus publicaciones más recientes se encuentra "The accompanying process of undocumented forced and repatriated migrations by transit countries. The case of Mexico" (2019), en "Migration and Health current challenges and opportunities". Es Graduate student award, University of California, Berkeley, The Health Iniciative of the Americas, PIMSA. $\mathrm{PhD}$ student visitor en el Institute for Research on Migration, Ethnicity and Society REMESO, de la Universidad de Linkoping (liu), Suecia.

Dirección electrónica: jorgemcardiel@gmail.com

Registro ORCID: https://orcid.org/0000-0002-2627-4435

\section{Chantal Lucero Vargas}

Es Doctora en Ciencias Sociales con Especialidad en Estudios Regionales por El Colegio de la Frontera Norte, Maestra en Derechos Humanos y Democracia por la FLACSO-México y Licenciada en Derecho por la Universidad Autónoma de Baja California. Cuenta con un Master en Derecho Constitucional por la Universidad de Sevilla, España. Actualmente es Profesora-Investigadora del Instituto de Investigaciones Sociales de la Universidad Autónoma de Baja California. Entre sus publicaciones más recientes en temas de migración y derechos humanos se encuentran: "La construcción gradual de la política de contención migratoria en México" (2020) en Villafuerte D. y M.E. Anguiano (Coords.). Movilidad humana en tránsito: retos de la cuarta transformación en política migratoria; y "Último párrafo del artículo 32 constitucional. Su discrepancia con los estándares internacionales de derechos humanos con relación al derecho a la igualdad y no discriminación" (2019) en Boletín Mexicano de Derecho Comparado.

Dirección electrónica: luceroc@uabc.edu.mx

Registro ORCID: https://orcid.org/0000-0003-0696-2617 